\title{
POLÍTICA EXTERIOR ARGENTINA: DE MENEM A DE LA RÚA ¿Hay una nueva política?
}

\author{
Raúl Bernal-Meza
}

\begin{abstract}
Resumen: El presente estudio hace un análisis de las políticas exteriores seguidas por los gobiernos argentinos en los últimos veinte años, con especial atención al período 1989-2001. Comparativamente, se analizan las políticas externas de Menem y De la Rúa, identificando en ellas las respectivas macrovisiones, su formulación y praxis, haciendo referencia en particular a los contextos hemisférico, subregional y bilateral (Brasil).

Palabras clave: política exterior argentina; Menem; De la Rúa.
\end{abstract}

\begin{abstract}
This article examines the last twenty years of Argentine foreign policy, with special emphasis on the period 1989-2001. The policies of Menen and De la Rúa are compared with regard to the formulation and implementation of their respective macro-visions, with particular focus on hemispheric and bilateral (Argentina-Brazil) relations.

Key words: Argentine foreign policy; Menem; De la Rúa.
\end{abstract}

$\mathrm{D}$ espués de una política exterior signada por el aislamiento, la ruptura y las contradicciones, que caracterizó el período del gobierno militar (19761983), el siguiente gobierno, constitucional y democrático, presidido por Raúl Alfonsín, introdujo tres cambios importantes respecto de los criterios ordenadores de la política exterior del régimen militar: el desplazamiento del modelo Este-Oeste y la resignificación de la "occidentalidad de Argentina"(diferenciar entre los intereses del bloque y los intereses de Argentina ${ }^{1}$ ); reformulación de la participación en No Alineados, cuestión que partía de la percepción del gobierno sobre la existencia de una confrontación de carácter "realista" entre dos grandes poderes y no de una "guerra santa", en la cual se involucraba todo occidente, lo que daba espacio a la continuidad de la permanencia del país en dicho foro; revalorización del eje Norte-Sur (Russell,1989), siendo este último segmento considerado el espacio natural y apropiado para la búsqueda de convergencias entre determinados intereses políticos y económicos del país y los de otras naciones del Tercer Mundo, aún cuando estas relaciones fueran pasadas por el tamiz de las "alianzas selectivas".

El marco determinante de la política exterior y su relación con la política interna fue una concepción predominante- mente "desarrollista". ${ }^{2}$ Esta interpretación sería abandonada bajo la nueva visión del mundo que traía consigo la comunidad epistémica ${ }^{3}$ del menemismo(Bernal-Meza, 2000).

Como ocurrió con otros países de América Latina, la Argentina abandonó el paradigma de relaciones internacionales del Estado-desarrollista, adoptando el paradigma neoliberal, cuyas reformas implícitas fueron rápidas y radicales (Bernal-Meza, 2000; Cervo, 2000).

El eje de la "nueva agenda" de la política exterior argentina de los noventa lo constituyó entonces la adopción integral de los "valores hegemónicos universalmente aceptados", ${ }_{4}^{4}$ porque de ellos resultaba el prestigio, la credibilidad y la confiabilidad externas. Estos valores, impuestos por el orden imperial configurado por la postguerra fría, significaban una confluencia de democracia (formal) y libre mercado, bajo una extraordinaria hegemonía ideológica del neoliberalismo, que se reflejaría en múltiples segmentos del sistema internacional. Así, el "Consenso de Washington" (1989), la "Iniciativa para las Américas" (1990) - de la que derivaría el proyecto ALCA-y la constitución de la OMC, junto a las nuevas disciplinas, que establecieron las normativas a las cuales debían ajustarse las políticas 
públicas, incluyendo el comercio internacional y las regulaciones financieras, pasaron a constituir los marcos según los cuales los gobiernos que los hicieron suyos, reformularon sus orientaciones y praxis de política exterior.

En este contexto, "el país (en realidad debería decir el gobierno) modifica su concepción del mundo, realiza un profundo viraje en su orientación internacional y define una nueva política exterior" (De la Balze;1997:107). Esto llevaba implícita una adhesión a la alianza occidental y sus principios de democracia y libre mercado; en términos de seguridad, adopción de los nuevos marcos de seguridad cooperativa, que implicaba, naturalmente, la renuncia a la construcción de misiles, y, en general al armamento químico, atómico y bacteriológico. Se reformularon así las concepciones y las políticas gubernamentales dominantes en el pasado: se abandonaron, definitivamente, las estrategias de sustitución de importaciones, que ya venían en crisis desde mediados de los setenta; ${ }^{5}$ se reformuló el papel del Estado, de las relaciones económicas y comerciales internacionales del país; se adoptó la interpretación según la cual los problemas argentinos eran de naturaleza puramente económica. Por lo tanto, en términos de la política interna, se supuso agotado el modelo económico desarrollista/estatista y, en términos del contexto externo para la política exterior, la globalización había disminuido las opciones y alternativas posibles y que fueran distintas a las emanadas de la visión ideológica y fundamentalista de ésta. ${ }^{6}$

La adopción de esta nueva alternativa implicaba -en términos de política exterior- tres posiciones básicas:

-una alianza con las potencias vencedoras de la guerra fría y un alineamiento con el hegemón, lo que conducía, naturalmente, al retiro del movimiento de los No Alineados;

- aceptación de las nuevas reglas de juego de la economía y la política mundiales en la construcción del "nuevo orden", que sería el determinado por las grandes potencias capitalistas. Este cambio implicaba adscripción a la agenda de "valores hegemónicos universalmente aceptados", especialmente en lo que se refería a las políticas de seguridad y los alineamientos en los distintos regímenes internacionales;

-profundización de los vínculos transnacionales de Argentina, ante la evidencia de encontrarnos frente a un mundo "global", lo que implicaba adhesión a las estrategias mundiales del capitalismo transnacional (Bernal-Meza, 2000). La Argentina, viéndose a sí misma como un país pequeño en el escenario internacional (según la visión de la comunidad epistémica), dió prioridad a la inserción en el mercado internacional de capitales, a partir de la evidencia de que esos flujos eran determinantes de su ciclo económico (Baumann, 2001:61), adoptando entonces políticas adecuadas a esa estrategia de inserción externa. El plan de "Convertibilidad" sería un elemento clave de esta, que, como se verá, De la Rúa mantendría bajo su gestión.

\section{FORMULACIÓN Y PRAXIS DE LA POLÍTICA EXTERIOR ARGENTINA: 1989-1999}

\section{La Agenda Internacional de los 90s.: Cómo Ésta se Estableció, para Identificar los Temas de la Misma}

Una particular, realista (en términos del reconocimiento a las jerarquías de poder mundial), pero a la vez sesgada y parcial interpretación del proceso de cambios internacionales y de las dificultades internas para lograr el desarrollo, constituyeron elementos clave, los que fueron utilizados para dar cuenta del cambio de política. Según Russell, los principales argumentos que permitieron al gobierno del presidente Menem justificar el cambio de la política exterior, fueron los siguientes:

- que el orden mundial emergente se caracterizaba por la interdependencia y la cooperación entre los países y por el triunfo categórico, aunque no universal, de una filosofía (democracia liberal);

- que en este orden existían condiciones para que la paz se sustentara más en la seguridad cooperativa que en el equilibrio de poder;

- que la globalización de la economía había hecho definitivamente obsoleto el modelo de crecimiento basado en la sustitución de importaciones;

- que este modelo, junto al aislamiento al que dio lugar, acarreó la decadencia relativa del país y, por ende, la pérdida de gravitación de Argentina en el orden internacional;

- que la relación preferente con Gran Bretaña fue una de las claves de la inserción exitosa de Argentina en el mundo a fines del siglo XIX y principios del XX; y

- que, en consecuencia, el país necesitaba encontrar y desarrollar, en forma pragmática, nuevas relaciones preferentes para asegurarse una nueva reinserción exitosa en el siglo XXI (Russell, 1993).

Variables Internas y Externas de la Formulación de "la Nueva Política Exterior Argentina" - En términos de 
"variables", de las externas fueron representativas: el carácter e ideología de la nueva alianza gobernante; su visión del mundo y el papel relevante de los actores y la comunidad epistémica que formulaban la política exterior; la posición respecto de las estrategias posibles de desarrollo; la cultura política dominante (nacionalismo territorial, vocación hegemónica o de liderazgo subregional y regional y los marcos institucionales: centralismo, presidencialismo y personalismo). ${ }^{7}$ De las variables externas: la nueva configuración del orden mundial y la agenda política internacional, con la predominancia de los temas económicos, que excluían todas la variables exógenas del desarrollo (dependencia científico-tecnológica y apartheid tecnológico; hegemonía ideológico-cultural y su visión sesgada sobre la naturaleza del desarrollo y el progreso).

\section{La Percepción del Escenario Mundial al Comenzar el} Gobierno - Según los hacedores de la "nueva política exterior argentina", era absolutamente necesario para que la Argentina iniciara un proceso sostenido de desarrollo producir cambios drásticos y sustanciales en la política exterior. Sin embargo, al interior de la comunidad epistémica, existieron dos interpretaciones acerca de la lógica que determinaba el nuevo curso de acción para la política exterior. Mientras que para Menem, Cavallo, Di Tella, Cisneros y los pensadores De la Balze, Fontana, Bolívar, J. Castro y otros, la necesidad de implementar la "nueva política" era consecuencia, fundamentalmente de los cambios ocurridos en el sistema mundial (fin de la guerra fría; Estados Unidos como única superpotencia mundial capaz de ejercer influencia y “jugar” en todos los escenarios: político-diplomático, militar-estratégico, tecnológico y financiero), para Carlos Escudé la necesidad del cambio de política, abandonando el aislamiento y el confrontacionismo con Estados Unidos era a-temporal, en el sentido que la adopción de tal modelo de política exterior era independiente de las condiciones derivadas del fin de la guerra fría; ${ }^{8}$ aún cuando también De la Balze señala que la política de reincorporación al Primer Mundo es anterior - temporalmente - al fin de la guerra fría, teniendo origen en los cambios económicos, sociales y políticos internos que ocurrieron en Argentina a partir de fines de 1983. Una diferencia se advertía, sin embargo, en el hecho que, con la excepción de Escudé - para quien una buena política exterior no necesariamente conduce al desarrollo - la mayoría de pensadores y formuladores consideraban que ésta, de por sí, aseguraba beneficios inmediatos. No obstante, el formulador del realismo periférico señalaba claramente que una "buena polí- tica exterior" (es decir, la que en su formulación él considera como tal), eliminaba los obstáculos que se presentaban a los objetivos de la política externa.

A su vez, otra diferencia, al interior de la comunidad se encontraba también entre las argumentaciones de Di Tella y de las de Escudé. Mientras este último insistía en la irrelevancia de las condiciones sistémicas, para el canciller había que cambiar porque el mundo estaba cambiando.

La formulación de Carlos Escudé, que éste denominó como realismo periférico $(1989 ; 1992 ; 1995)$, se transformó en el paradigma de la "nueva" política exterior argentina. La misma dominaría la formulación y praxis de la política exterior durante toda la década de los noventa, proyectándose su influencia en el gobierno siguiente.

\section{La Evolución de la Agenda y la Definición de Objetivos}

Identificación de los Temas que la Integraban - La fundamentación del núcleo duro de la agenda política lo constituyó entonces la "reinserción de Argentina en el mundo desarrollado". Esta visión, que se sostenía sobre el revisionismo histórico, suponía que el país, por propia voluntad y como consecuencia de la aplicación de cincuenta años de políticas externas equivocadas y confrontacionistas con la potencia hemisférica, había abandonado el eje binario del desarrollo, al que el (supuestamente) exitoso modelo agroexportador de subordinación a la hegemonía británica la condujera durante su vigencia (18801930). El objetivo entonces de la "nueva política" era volver a la Argentina al segmento del que nunca debió haber salido: es decir, el desarrollo.

Para esto, se implementó una estrategia que permitiera las más amplias coincidencias con la agenda externa norteamericana y los "valores hegemónicos universalmente aceptados":

Hubo así coincidencia con los temas dominantes de la política y la agenda internacional de Estados Unidos: democracia y libre mercado; seguridad cooperativa y "nuevos temas" (narcotráfico, medio ambiente, etc.).

Los Temas de la Agenda y su Jerarquización - De acuerdo con el razonamiento que justificaba el cambio, se puso en marcha una política exterior ordenada alrededor de cuatro ejes, todos ellos estrechamente relacionados. El primero de ellos era el abandono de las posiciones de confrontación política con los países desarrollados, el segundo, estrechamente ligado al anterior, fue que el bajo perfil político en las cuestiones que ocasionaban confrontaciones 
o fricciones con los países desarrollados no implicaba ceder espacios en aspectos que se referían al desarrollo económico del país; el tercero, planteado como una cuestión de objetivos y estilo señalaba que Argentina no podía ni debía pretender un alto perfil, ni mucho menos una posición de protagonismo internacional; ${ }^{9}$ por último, el apoyo al funcionamiento efectivo del sistema establecido en la carta de la ONU para garantizar la paz y la seguridad internacionales.

Los Objetivos - Di Tella, refiriéndose al gobierno del presidente Carlos Menem, señaló que "en el inicio de su gestión, la presente administración se propuso un cambio drástico como prioridad de nuestras relaciones exteriores. Se trataba, sintéticamente, de terminar con una tradición de aislamiento internacional y con conductas largamente erráticas y perjudiciales para los intereses argentinos (...). Lo que se ha hecho desde 1989 hasta ahora fue devolver el país a su posicionamiento normal, a las alianzas que le corresponden tanto por su historia como por vocación e interés. Esto significa cooperación con los países de la región y firme ubicación en Occidente, compartiendo los valores democráticos, el respeto a los derechos humanos, la economía de mercado y el comercio libre y abierto. (...); la credibilidad, la confianza y la transparencia fueron las notas decisivas de esta política de cara al mundo..." (Di Tella;1998:13-17). El eje central de la política exterior argentina pasaba por la nueva relación con Estados Unidos (Cisneros;1998:114-15).

El objetivo central o estratégico de la "nueva política exterior”, según sus policy makers (Menem, Cavallo, Di Tella) y su comunidad epistémica era "favorecer la reinserción de la Argentina en el Primer Mundo" (Escudé, 1989;1992;1995; Cisneros,1998; De la Balze, 1998; Castro,1998; Bolívar,1998). Dentro de ese núcleo, el objetivo más evidente fue construir una relación especial, una alianza de largo plazo con Estados Unidos. A éste le siguieron la recomposición de las relaciones con Europa ${ }^{10}$, a través de la profundización de las relaciones económicas y comerciales, así como con Japón; por último, la construcción de una alianza económica con Brasil (que, en realidad, se había iniciado en el tiempo de los acuerdos Alfonsín-Sarney). Seguidamente, ubicar al país en los nuevos escenarios de expansión y dinamismo del capitalismo mundial: la región Asia-Pacífico. Sin embargo, muchos de los objetivos pasaban por una "cuestión de imagen": en la medida que había un reconocimiento a la Argentina se consideraba que había progresos en el proceso. Así, uno de los objetivos también fue obtener el ingreso del país a la OCDE y la incorporación como miembro pleno a la Asociación de Cooperación Económica de Asia-Pacífico (APECC), objetivos que no fueron alcanzados.

Así, de la descripción de objetivos se desprende que existió:

- Una argumentación coincidente con la de autores de la comunidad epistémica: la tradición de un supuesto "aislamiento internacional"; el retorno a alianzas que le corresponden por historia y vocación y la apelación a la credibilidad externa.

- La adopción de la "agenda de valores hegemenónicos universalmente aceptados".

Estilo - Como argumentó en su momento el canciller Cavallo, la política exterior no podía seguir siendo interpretada en forma aislada, de modo que se trató de integrarla formando parte del programa de gobierno del presidente Menem, que se propuso introducir profundas transformaciones en procura de un aumento del bienestar del pueblo. De acuerdo a esa lectura, la situación, entonces, "tenía toda las características de un verdadero reto generacional: debimos adoptar una actitud comprometida y eficaz, alejada de la tentación metafísica del principismo estéril, procurando una respuesta capaz de sustraernos de la periferia del panorama mundial (...). Decidimos movernos con un sentido pragmático de la realidad, prefiriendo explotar las posibilidades concretas en desmedro de las especulaciones doctrinarias a las que habían sido propensas, desafortunadamente, algunos de nuestros predecesores (...). Entendimos que nuestra diplomacia debía ser activa y dinámica porque partiendo de la realidad y operando sobre ella, nuestro país podía llevar a cabo la mejor defensa de sus intereses y ubicarse adecuadamente en el concierto internacional" (Cavallo,1996:357-78).

En relación al estilo de conducción, hubo un elemento de continuidad desde 1984, la "diplomacia presidencial". Sin embargo, durante la gestión del presidente Menem hubo una excesiva concentración de la conducción de los asuntos externos al nivel presidencial. Las exageraciones, la sobreactuación, la permanente aspiración al protagonismo, rompieron con el perfil más sobrio y reposado que le confirió al estilo la conducción de Alfonsín. Asimismo, a la relación más cautelosa del primer canciller (Cavallo), respecto de la diplomacia de carrera, le siguió el estilo de Di Tella, mucho más prescindente de las opiniones de la burocracia diplomática (Busso y Bologna, 1994). 


\section{Constantes, Coincidencias y Rupturas en la Política Exterior Argentina de Alfonsín a Menem}

El cambio más drástico de la política exterior se dio respecto de Estados Unidos y del Brasil. Respecto del primero, se abandonó la búsqueda de autonomía y se buscó permanentemente la alianza y el alineamiento. El objetivo fue construir una "relación especial con Estados Unidos". Respecto del segundo, se redujo la importancia en la relación bilateral en el ámbito de la integración, aún cuando se buscaron mayores coincidencias en los temas vinculados a la seguridad y el fortalecimiento de la confianza mutua. Sin embargo, estos objetivos se sustentaban en la herencia de búsqueda de cada vez mayores entendimientos políticos con Brasil, heredados del gobierno de Raúl Alfonsín.

Según Jorge Bolívar, "la nueva política exterior argentina ofrece una fuerte identidad continental americana, que va desde la alianza estratégica con los EE.UU. a la integración de un mercado común (el Mercosur) con sus países vecinos: Brasil, Uruguay, Paraguay, con el agregado de Chile y Bolivia (...). Además, nuestra Nación se expresa plenamente en las figuras dominantes del nuevo orden planetario: la democracia y la economía libre. Se muestra integracionista y comprometida con la defensa del nuevo ordenamiento mundial en el ámbito de Naciones Unidas, contrastando con su anterior perfil dominado por un aislacionismo internacional de hecho"(Bolívar,1998), que encuentra sus "antecedentes conceptuales en una interpretación correcta de las tendencias profundas que caracterizan el escenario mundial contemporáneo" y cuyos pilares son la "reinserción en la economía mundial", "una alianza con Estados Unidos", "la integración económica, de cooperación política y de alianza estratégica con Brasil", una política de seguridad y defensa orientada a crear una Zona de Paz en el Cono Sur de América” y en una "política de prestigio" fundada en la reafirmación de ciertos principios universales y en el desarrollo de un sostenido esfuerzo de cooperación y solidaridad con el resto de los países de América Latina (De la Balze;1998).

\section{Síntesis de Agenda argentina 1989-1999:}

- Proyección externa de la "reformulación de la estrategia nacional de desarrollo".

- "Reinserción" en el Primer Mundo.

- Adopción de la "agenda de valores hegemónicos universalmente aceptados" (o Agenda de las potencias industrializadas de occidente).

- Crear para Argentina una "zona de paz" en el cono sur.

\section{Síntesis Objetivos de la política exterior argentina 1989- 1999:}

- Cambiar las relaciones estructurales e históricas con Estados Unidos (confrontacionismo, aislamiento). Buscar una alianza y relación especial, adoptando un conjunto de políticas que son vistas como convenientes para ese objetivo, en particular las vinculadas a la seguridad y la defensa.

- Afirmación de la democracia, de la libertad y de los derechos humanos.

- Obtener mejores condiciones para el desarrollo, desde la perspectiva dominante del neoliberalismo.

- Ingresar a la OTAN y a la Organización de Cooperación y el Desarrollo Económico (OCDE).

- Impulsar la integración bilateral con Brasil y Chile.

- Profundizar los vínculos con la Unión Europea y Japón.

- Participar activamente en la ONU y especialmente en sus operaciones de paz.

Síntesis del Carácter de la Política Exterior 1989-1999 - Al amparo del Ejecutivo (Menem, Di Tella), surge una comunidad epistémica que cambia la política exterior tanto en su agenda como en sus objetivos y le impone un estilo activo y dinámico en la formulación de propuestas e iniciativas, marcadas, esencialmente por sus contenidos de "alta política", con una fuerte y permanente concentración en los temas de la seguridad, el intervencionismo y las medidas vinculadas al logro de un nuevo y distinto perfil de relacionamiento con Estados Unidos, basado en el realismo de la subordinación al poder y en el pragmatismo del alineamiento a sus políticas y agenda internacional. El alto perfil de la política exterior se caracteriza por una fuerte diplomacia presidencial y un activismo protagónico.

En síntesis, tomando el concepto de cambio, según Russell, como "el abandono o reemplazo de uno o más de los criterios ordenadores de política exterior" (Russell, 1989), desde mi perspectiva, en la Argentina, durante el período de las dos presidencias de Carlos Menem, hubo dos tipos de "cambios", en relación al pasado reciente (el gobierno de Alfonsín): los de naturaleza básica (o lo que Russell denomina como "criterios orientadores"); los cambios que son consecuencia de la adopción de nuevos criterios ordenadores en la política exterior, considerando éstos como "instrumentales" para la implementación de los primeros.

De esta forma, los cambios de la primera tipología fueron: - en las relaciones con Estados Unidos: es decir, el cambio de alianzas esenciales desde una visión de compromisos 
y coincidencias, también pertenencia, con el mundo en desarrollo o Tercer Mundo (Grupo de los 77, No Alineados, etc.) hacia una alianza estratégica con Estados Unidos y el grupo de potencias capitalistas de occidente, vencedoras de la guerra fría, que conforman un grupo, al cual la Argentina (en la suposición de la comunidad epistémica) pertenece por naturaleza y que abandonó por propia voluntad. Es lo que De la Balze denomina como "política de reincorporación al primer mundo" y el desarrollo de una alianza especial con la mayor potencia mundial.

Sin embargo, en esto no hubo nada nuevo, respecto de la visión que bajo el régimen de "Reorganización Nacional" (1976-1983) ya tuvieron los militares, acerca de la pertenencia de la Argentina, aunque sí cambió el estilo y el contenido más radicalizado ahora de la política pública que debía acompañar este cambio (adopción del modelo neoliberal; liberalización de los mercados, privatizaciones, ajuste, etc.).

- en las negociaciones por Malvinas, formulando una nueva línea de acción frente a Gran Bretaña, aceptando con realismo el hecho que la posesión efectiva de las islas está en manos británicas y que esa situación difícilmente vaya a cambiar, frente a lo cual surge un camino de acción que se mueve entre los extremos de entregar o vender las islas a los kelpers (Escudé) u olvidarse definitivamente del asunto hasta que las cosas, en términos de poder relativo, cambien para la Argentina, pasando por la "asociación" (Di Tella). ${ }^{11}$ Los cambios de la política se concentraron en los siguientes aspectos: a) restablecimeinto de relaciones consulares y luego diplomáticas con Gran Bretaña, b) aplicación del "paraguas de soberanaía"; ${ }^{12}$ se declaró el cese formal de hostilidades y se dejó de lado la presentación del tema Malvinas en la Asamblea General de la ONU; c) se inició una serie de acuerdos de cooperación (firma de acuerdos pesqueros y petroleros; autorización para el viaje de familiares de combatientes argentinos muertos a visitar el cementerio en las islas; restablecimiento de los viajes aéreos desde el continente, tocando territorio argentino; realización de diálogos radiales a través de la BBC, entre el canciller Di Tella y los kelpers, como parte de la "nueva política" de seducción, etc.).

Los cambios de la segunda tipología fueron:

- el giro en la política nuclear y la firma de los acuerdos de no proliferación.

- el abandono de la política misilística y el ingreso al MTCR.

- el retiro del Movimiento de No Alineados, en la medida que la agenda de éste ya no permitía coincidencias con la nueva política exterior argentina de alianza con occidente y adopción de la "agenda de valores hegemónicos universalmente aceptados".

- modificación de los votos en la ONU, para acercar las posiciones a aquellas defendidas por Estados Unidos.

- modificación de la posición respecto de Cuba en la Comisión de Derechos Humanos de la ONU, con el fin de ajustarla a las expectativas de Estados Unidos.

- abandono de la posición de neutralidad en los conflictos internacionales en los cuales el país no está involucrado directamente (guerra contra Irak; aceptación implícita de la invasión norteamericana a Panamá y de las intervenciones de la OTAN en Yugoslavia; eventuales intervenciones en conflictos internos como en el caso de Colombia), participando así activamente de las estrategias militares y de seguridad de Estados Unidos.

- reformulación de las políticas de seguridad, adhiriendo a la nueva visión norteamericana de "seguridad cooperativa".

- búsqueda de una incorporación a la OTAN, en la medida que ésta podía reflejar el nivel de resultados del cambio de la política respecto de Estados Unidos y podía confirmar el buen camino del objetivo de "reinsertar a Argentina en el mundo desarrollado".

En tanto, las continuidades con el gobierno de Alfonsín estuvieron dadas por:

- La profundización de la integración económica con Brasil.

- La integración física de infraestructura, así como la cooperación económica, política y militar con Chile.

- La pertenencia al Grupo de Río, aún cuando el involucramiento argentino sería significativamente menos intenso en relación a la "agenda latinoamericana del foro". ${ }^{13}$

- La aplicación del paradigma del realismo periférico, como una lectura "realista" de la necesaria subordinación al poder hegemónico. Éste fue un permanente frente de profundas diferencias con Brasil, en la medida que para este último país, de acuerdo a sus objetivos de país intermédiario, la búsqueda de mayores recursos de autonomía (recurriendo al multilateralismo y al universalismo selectivo) pasaba, necesariamente, por buscar las formas de reducir el poder de los grandes o, al menos, de reducir las diferencias de atributos de poder entre éstos y el país.

En el caso de Argentina no puede hablarse de "parcerías estratégicas", en la medida que la búsqueda de un alineamiento estratégico con Estados Unidos anulaba las 
eventuales alianzas con otros, cuando las agendas de estos últimos no fueran coincidentes con la norteamericana. Esto sucedió en el relacionamiento con Brasil, donde, a pesar de la coincidencias en términos de las percepciones dominantes sobre el "orden mundial" y la "globalización", las agendas brasileñas y norteamericanas diferían en cuestiones esenciales, como la política de seguridad, el comercio, las interpretaciones sobre la ubicación geográfico-política de los problemas del medioambiente, etc.

Por último, hasta 1997 (Reunión de Belo Horizonte), Argentina sigue una política de double standing, respecto de las relaciones económicas hemisféricas: entre optar por ALCA o profundizar el Mercosur. En relación a Brasil, éste no fue la prioridad de la política exterior.

\section{DE LA RÚA, LA ALIANZA UCR-FREPASOY LA POLÍTICA EXTERIOR DEL 2000: CAMBIOS Y CONTINUIDADES}

\section{Las Definiciones de la Política Externa}

Si bien durante la campaña electoral no hubo abiertas o manifiestas declaraciones que hicieran presumir drásticos cambios en la política exterior, respecto de aquella seguida por Menem, la ciudadanía votó en forma mayoritaria, evidentemente, por "cambios en general".

Desde los primeros días de su gestión (diciembre de 1999), el nuevo gobierno buscó diferenciarse del anterior. No obstante, como esos esfuerzos no se advirtieron en el plano de la política económica - ya que en el primer año y medio de gobierno De la Rúa aplicaría tres grandes ajustes, que afectaron exclusiva y directamente a los trabajadores, asalariados y clases medias- se hicieron abiertas declaraciones respecto de una gestión diferenciada del ministerio de Relaciones Exteriores, a cargo de un economista conservador, como era Adalberto Rodríguez Giavarini.

En el discurso del 21 de diciembre de 1999, en ocasión de poner en funciones a sus colaboradores inmediatos, el canciller expresaba que el nuevo camino elegido por los ciudadanos (al haber optado por la Alianza), favorecía la ampliación democracia. Hacer del ministerio de Relaciones Exteriores un instrumento que colaborara en la generación de una nueva e imprescindible "previsibilidad y confiabilidad" vis-à-vis el mundo desarrollado, implicaba coherencia en las iniciativas y decisiones y la elaboración de políticas de Estado sobre aquellos considerados como "intereses primordiales" del país: la integración política y económica sudamericana como un objetivo central; el afianzamiento de la paz y la seguridad internacionales y la democratización del sistema internacional. ${ }^{14}$

De estas primeras líneas de política se podían percibir dos elementos relevantes: la integración (Mercosur, América del Sur) y la adscripción a una visión más bien ética y normativa sobre el sistema internacional.

Algunos meses más tarde, el nuevo canciller señaló que la agenda de la política exterior argentina no se trazaría "sólo por los intereses, sino también por los valores compartidos". La nueva política marcaría una diferencia, porque "mientras intenta profundizar las relaciones políticamente indispensables, pretende no dejar fuera a ningún país del mundo". ${ }^{15}$ Implicaba un mensaje de adhesión a la política exterior norteamericana (la apelación a los valores compartidos), que no excluía a aquellos gobiernos latinoamericanos que los compartían) y, a la vez, señalaba cuál sería la diferencia: Cuba.

Bajo la presión de la situación económica y financiera interna y, en buena medida por propia adscripción a los lineamientos de la nueva agenda de valores impulsadas por las democracias desarrolladas, la Argentina acompañó el voto norteamericano de castigo a la Isla en la Comisión de Derechos Humanos de la ONU en el año 2000.

Según la prensa, este tema provocó el primer debate de naturaleza ideológica en el seno del gabinete nacional (Cardoso, 2000). Esta discusión profundizaba los desencuentros sobre la política en general, mientras los críticos, internos y externos, señalaban que el nuevo gobierno no había abandonado el alineamiento automático ni las relaciones carnales, ${ }^{16}$ ni tampoco había aplicado el cambio de estrategia: fortalecer al Mercosur para negociar, desde una mayor calidad y capacidad, con Estados Unidos por ALCA. El nuevo gobierno reiteró su posición frente a Cuba, por segunda vez consecutiva, en 2001. La Argentina votaba la moción de condena junto a Estados Unidos, la Unión Europea y Uruguay, mientras que Brasil nuevamente se

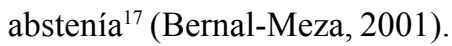

Respecto a la comunidad internacional, el nuevo gobierno argentino considera a las Naciones Unidas como el ámbito más adecuado para las negociaciones internacionales y la obtención de consensos multilaterales. Ha declarado su aspiración a que se logre una mayor democratización del organismo, especialmente de su Consejo de Seguridad. El aumento del número de miembros permanentes, según la posición argentina, debe realizarse teniendo en cuenta la representación regional, sin alterar la igualdad y las posibilidades de participación de los países de cualquier región. 
En relación al tema "Malvinas", el gobierno de De la Rúa decidió modificar la línea de conducta seguida por el gobierno anterior. En ese sentido, impulsó la reanudación de las negociaciones sobre la disputa por la soberanía de las islas, de acuerdo a las resoluciones de las Naciones Unidas y abandonó la política de "seducción a los kelpers", iniciada por la gestión de Di Tella y que implicó considerar a éstos como parte de las gestiones diplomáticas por las negociaciones sobre la soberanía de las islas. ${ }^{18}$ El cambio más significativo se relaciona con la reintroducción del tema en los debates de la Asamblea General de la ONU, donde éste no se trataba desde 1989. La modificación obedece, en primer lugar, al convencimiento que la política de "seducción" y cooperación seguida por Di Tella no dio ningún resultado y, en segundo lugar, porque la ONU le brinda a la Argentina el único foro que puede servirle como instrumento de presión frente a Gran Bretaña.

\section{Las Relaciones con Estados Unidos y Alca}

De la Rúa y su canciller impulsaron una línea de política que mantuviera el nivel de buen relacionamiento que las relaciones bilaterales argentino-norteamericanas tuvieron bajo la gestión del presidente Menem, pero reduciendo el perfil de exposición ("relaciones carnales"), interpretadas -interna y externamente- como de seguidismo o alineamiento. El canciller argentino definió lo que serían las nuevas relaciones bilaterales como "intensas".

La agenda política se ha caracterizado por una mayor importancia asignada a los temas de baja política: economía, comercio y finanzas. En cuestiones de seguridad internacional, la Argentina aceptó la petición norteamericana de mantener su misión de gendarmes en Haití.

El principal problema bilateral radica en el rechazo norteamericano a la Ley de Patentes Medicinales, promulgada por la Argentina. Otro problema, planteado por EE.UU. y que podría afectar el status que tienen los argentinos de ingresar sin visa a ese país es el tema de las dogras y la situación de la llamada "triple frontera". ${ }^{19}$ Una tercera diferencia se relaciona en un conflicto entre la CIA y la SIDE (Secretaría de Inteligencia del Estado) argentina.

Durante los primeros meses de la gestión de De la Rúa, dos misiones económicas norteamericanas visitaron Buenos Aires, para presionar sobre el tema de las patentes, la lucha contra la corrupción, la adjudicación de los nuevos sistemas de radares para aeropuertos ${ }^{20}$ y la política de cielos abiertos para el cabotaje, inicialmente prevista para comenzar a regir en el 2003. Sobre el primer tema, el Secretario de Comercio de la administración Clinton, William Daley, en su primera misión ante el nuevo gobierno argentino, amenazó al país con denunciarlo ante la $\mathrm{OMC}$, en el caso que la Argentina cambiara la ley de patentes en vigencia, introduciéndole una cláusula que obligue a los laboratorios a producir en el país al menos una parte de los fármacos que se comercializan en el país. El juicio se inició, finalmente, a mediados de agosto del año 2000. En relación a la política de cielos abiertos, Estados Unidos presiona por una apertura total e irrestricta, cuyo carácter recíproco no asegura a las compañías argentinas sobrevivir frente a la eventual competencia norteamericana.

La preocupación del gobierno norteamericano sobre la "triple frontera" se relaciona con el supuesto de que los gobiernos con soberanía en la zona -y en particular el de Argentina, teniendo en cuenta los atentados producidos sobre representaciones israelitas, que provocaron más de cien muertos- no ejercen los debidos controles y seguimientos antiterroristas ni de seguimiento sobre las eventuales ramificaciones de células terroristas islámicas que operarían en la zona. Por último, en relación al conflicto entre las dos agencias de inteligencia, el mismo se ha transformado en el más espinoso problema político entre ambos gobiernos. El jefe de la estación porteña de la CIA, Ross Newland, denunció que la SIDE espiaba la actividad de los agentes norteamericanos en Argentina y que no prestaba atención a los pedidos de cooperación, en particular en el control de la embajada rusa en Buenos Aires. Según la prensa, el Secretario de Estado, Colin Powell, planteó el problema al canciller Rodríguez Giavarini, durante la entrevista que ambos sostuvieron en Washington, durante la segunda semana de mayo pasado. La situación, identificada como "el punto más ríspido de la relación con el gobierno de Bush", llevó a la suspensión de la relación entre las dos agencias de inteligencia y la CIA habría levantado su estación "formal" en Buenos Aires. ${ }^{21}$

No obstante estas diferencias, el apoyo del nuevo gobierno norteamericano de George Bush Jr. fue fundamental para que Argentina consiguiera, a comienzos del año 2001, el "blindaje" por 40.000 millones de dólares, acordado por el FMI y la participación de otros gobiernos, en particular de España. Pero no estuvo dispuesto a aportar nuevos recursos, transfiriendo la responsabilidad al FMI. Esta fue también la posición 
adoptada frente al rebrote de la crisis financiera, entre fines de junio y el mes de julio de 2001. A pesar de ese apoyo, el gobierno norteamericano, siguiendo la línea conducta de Clinton durante sus últimos años, señaló que no brindaría apoyo financiero directo a Buenos Aires.

En relación a los temas hemisféricos, a diferencia de la política con contenidos más intervencionistas de Menem, De la Rúa no apoyó el "Plan Colombia", diseñado e implementado por la administración Clinton. En la "Cumbre de Brasília" (31 de agosto de 2000), el presidente argentino expresó su apoyo al gobierno constitucional de Colombia y reivindicó las políticas de no intervención, acercándose en este sentido a la posición sostenida por Brasil.

Por el otro tema hemisférico de relativa importancia para Estados Unidos, ALCA, el gobierno norteamericano, buscando el debilitamiento de la posición más dura de Brasil frente a las negociaciones futuras y creando una situación de fractura en el Mercosur, ofreció a la Argentina negociar un acuerdo bilateral de comercio, similar al que la potencia está negociando con Chile, pero el mismo fue rechazado por el gobierno argentino.

La opinión del negociador argentino, Horacio Chighizola, expresada meses atrás, sostenía cuatro premisas básicas sobre las cuales se diseñó la negociación frente a ALCA:

- la decisión de negociar como parte de un bloque subregional, presentando una posición única y coordinada en todas las áreas sustantivas;

- la intención de contar con una agenda lo suficientemente amplia como para permitir un avance equilibrado, que refleje los intereses de todos los participantes del proceso, de manera de reducir las asimetrías iniciales existentes. La agenda amplia debería reflejar un equilibrio entre los llamados "nuevos temas de la agenda multilateral" (servicios, inversión, propiedad intelectual), propuesta principalmente por Estados Unidos y Canadá, y los viejos temas de dicha agenda multilateral (acceso a mercados, agricultura, subsídios);

- el convencimiento de que el ALCA redundaría en beneficios para la región, en la medida en que contemplara los intereses particulares de los participantes;

- el reconocimiento de la necesidad de lograr un acuerdo con derechos y obligaciones comunes para todos los participantes del proceso. La decisión es no permitir el establecimiento de otros ALCA diferenciales, es decir, con previsión de derechos y obligaciones diferentes, dependiendo del nivel de desarrollo del país (Chighizola, 2000:16-18).

\section{El impacto de la Predisposición Argentina a Negociar ALCA}

El gobierno del presidente Menem nunca desechó por completo las posibilidades de conseguir un acuerdo bilateral con Estados Unidos o adelantar las negociaciones por ALCA. Estas dudas derivaban de dos situaciones: en primer lugar, las posiciones en el seno del gobierno, entre quienes perferían un acercamiento a Estados Unidos y ALCA, por sobre las relaciones con Brasil ("comunidad epistémica", Cavallo, Di Tella) y aquellos que querían mantener la prioridad del eje sudamericano (niveles intermedios de Economía y de la Cancillería, así como también, en parte, el propio Menem). En segundo lugar, porque algunos sectores, tanto de gobierno como de la sociedad (grupos económico-financieros), consideraban que el arancel externo común era un impedimento para la toma de decisiones que mejoraran la competitividad de la economía argentina.

Desde 1994, un documento interno (non paper) de la Cancillería argentina señalaba algunas contradicciones de la unión aduanera del Mercosur con los objetivos de corto plazo de la Argentina. Allí se decía que lo que el país necesitaba era contar con mayores grados de libertad en la política económica, para equilibrar su balanza comercial, sin afectar su nivel de actividad, algo que la resignación de instrumentos de política comercial que imponía la unión aduanera hacía incompatible (Bernal-Meza, 1994:274).

Con el nuevo gobierno, dentro de los poderes especiales que solicitó Cavallo para enfrentar la crisis estaba una mayor injerencia de Economía en la gestión de la polítia exterior. No está claro aún cuánto de este espacio le fue asignado por De la Rúa, pero lo cierto es que el autor de la "Convertibilidad", desde su retorno a la actividad oficial, se ha caracterizado por sus permanentes declaraciones públicas, sobre Mercosur, ALCA y las relaciones con Brasil. ${ }^{22}$ Muchas de ellas han evidenciado abiertas contradicciones con los dichos del canciller Giavarini y del propio De la Rúa.

El giro a la derecha que ha realizado el gobierno de De la Rúa, constituyendo una nueva alianza de apoyo con Cavallo, potencia las posiciones de los sectores más liberales que siempre vieron mejor la alternativa ALCA que la profundización del Mercosur. Machinea, antes de dejar su cargo en el ministerio de Economía (febrero de 2001), ya hablaba de anticipar las negociaciones de ALCA.

Sin embargo, el canciller argentino rechazó el ofrecimiento que, de manera informal, le efectuó el gobierno norte- 
americano, para negociar un acuerdo bilateral de libre comercio como el que EE.UU. está negociando con Chile. El canciller Rodríguez Giavarini señaló que las negociaciones para ingresar al ALCA se realizarán a través del Mercosur, reiterando que "nosotros cumplimos con los tratados internacionales, nuestros compromisos con el Mercosur y negociaremos a través de él". ${ }^{23}$

Sin embargo, la presencia de dos opiniones distintas en el gobierno argentino crean un manto de dudas sobre el Mercosur y debilitan aún más su imagen externa. Un diplomático brasileño señaló que "a chancelaria argentina revela que o país quer manter a união aduaneira. Mas, com essa divisão interna na Argentina, não se pode esperar que haja espaço para grandes inovações no bloco". ${ }^{24}$

Cavallo representa la continuidad de vigencia del pensamiento de sectores que fueron dominantes bajo el menemismo (su "comunidad epistémica": alianza con Estados Unidos, visión de la integración del Mercosur como un camino de liberalización comercial hacia ALCA; percepciones críticas sobre Brasil, tanto hacia su política externa-particularmente frente a Estados Unidos, que es vista como conflictiva y distorsionadora de una necesaria comunidad de intereses hemisféricos-como respecto de la capacidad de sus dirigencias gubernamentales para generar escenarios económicos de estabilidad) y también de sectores actuales del radicalismo (gobierno) y de la cancillería.

Desde este sector, hoy identificado en la figura de Cavallo, dos problemas separan a Argentina de Brasil: los escenarios probables para Mercosur y la posición frente a Estados Unidos y ALCA.

Respecto del primero, mientras este grupo impulsa un retroceso del Mercosur hacia una zona de libre comercio, Brasil (en principio) apoyaba la continuidad o statu quo actual del bloque. En relación al segundo, en tanto este sector argentino está a favor de la propuesta norteamericana de acelerar la firma de tratados bilaterales de comercio, Brasil impulsa una negociación de bloque y lo más tarde posible, es decir lo acordado (2005). Como señaló la prensa, "Cavallo quiere flexibilizar el encuadramiento del Mercosur y acercarse, con alianzas bilaterales, a Estados Unidos. En la cancillería prefieren no irritar a los brasileños y no volver a las relaciones carnales". 25

\section{Las Relaciones Bilaterales con Brasil y su Incidencia sobre el Mercosur}

Hasta 1997 (Belo Horizonte), Argentina sigue una política de double standing, respecto de las relaciones económicas hemisféricas: entre optar por ALCA o profundizar el Mercosur. El hecho que el Brasil no constituyera una prioridad para la política exterior de Menem y la búsqueda constante de un mayor acercamiento a Washington fueron motivos definitorios para que las relaciones bilaterales no pasaran del umbral de interdependencias restringidas al ámbito comercial del Mercosur y de la búsqueda de los entendimientos señalados en materia de seguridad.

En los hechos más visibles, desde la devaluación del real las relaciones bilaterales venían deteriorándose. Desde su arribo, el gobierno de De la Rúa intentó fortalecer la relación. Así, hasta el desencadenamiento de la "nueva etapa de crisis", con las medidas implementadas por Argentina entre marzo y julio pasados (2001), ambos países habían realizado pequeños progresos en su relacionamiento mutuo, en relación al Mercosur.

El 28 de abril de 2000, los ministros de Relaciones Exteriores de ambos países firmaron un documento reservado, con el fin de disminuir el impacto institucional de nuevas crisis en el Mercosur. Para ello, se avanzó en la previsibilidad, estableciendo como fecha el mes de marzo de 2001 para comenzar la aproximación de las políticas económicas. El primer paso fue hacia la estandarización u homogeneización de las estadísticas económicas recopiladas por los órganos específicos de cada país. Posteriormente, en la Cumbre de Florianópolis, a mediados de diciembre de 2000, Argentina y Brasil avanzaron en varios aspectos. En primer lugar, se revisó la forma cómo se resolverían las controversias que surjan en el futuro, ratificándose la situación de "estudio" para la creación de un Tribunal Arbitral Permanente para resolver los conflictos comerciales del bloque, algo que permitiría al Mercosur adquirir una mayor seguridad jurídica. En segundo lugar, avanzando hacia una mayor liberalización unilateral del comercio, los países del Mercosur acordaron reducir en medio punto el AEC, a partir de enero de este año. Por último y en lo que respecta a la situación futura de la armonización y coordinación específica, se acordó ésta a partir del 2002, sobre la base de las variables macroeconómicas, con metas fiscales y de inflación comunes.

Finalmente, en Asunción (14 de junio de 2001), argentinos y brasileños presentaron un proyecto común de decisión para crear un grupo de alto nivel que revea toda la estructura del AEC. Posteriormente, en Brasília, Cavallo y Malán convinieron en apostar a la zona de libre comercio, flexibilizando (diluyendo) el arancel externo común, 
aunque sin hacer desaparecer la unión aduanera, lo que aparece como difícil de compatibilizar.

Como se podrá apreciar, en realidad no hay discordancias respecto de ALCA y Mercosur entre las posiciones de ambos países, pues, en los hechos, la reducción progresiva del arancel externo común ${ }^{26}$ (con el acuerdo del Brasil) tiende a perforar hacia abajo el AEC, disminuyendo la protección, acercándose así cada vez más a una ZLC. Por otra parte, en tanto la posición oficial del gobierno argentino es respetar las fechas convenidas en las negociaciones Mercosur-Estados Unidos, el problema central, que era la reticencia y hasta la oposición brasileña a ir hacia un ALCA, quedó en la nada después que Cardoso aceptara oficialmente en Québec la propuesta norteamericana, en los plazos y condiciones convenidos desde Belo Horizonte (1997).

Sin embargo, el nivel de estancamiento del Mercosur y la falta de decisión política del Brasil para impulsar iniciativas de "relanzamiento", asociado a la presencia de actores políticos que manifiestamente declaran su perferencia por un mayor acercamiento a Estados Unidos, agregan incertezas sobre el destino futuro del bloque y sobre los compromisos argentinos con el Tratado de Asunción. Se considera que el Mercosur, en el estado que se encuentra no es satisfactorio No obstante, éste constituye "política de Estado" y, de acuerdo a la Constitución Argentina, por el hecho que los tratados internacionales incluídos en ella (como es el caso del de Asunción) tienen jerarquía superior a las leyes, generando derechos exigibles ante los Tribunales de Justicia nacionales, la decisión política gubernamental tiene claros marcos determinantes acerca de sus alcances.

\section{La Nueva Política Arancelaria y Monetaria}

El nuevo programa del ministro Cavallo, el "Plan de Competitividad", resultó ser, en los hechos, un programa heterodoxo, que mantenía lineamientos de la política monetarista, (continuidad de la Convertibilidad, aumento de la recaudación, reducción del déficit fiscal), pero le agregaba un componente proteccionista, al aumentar los aranceles externos.

La suba de aranceles tiene varias lecturas, de las cuales derivan incógnitas sobre el destino futuro del AEC y, en definitiva, sobre la naturaleza del Mercado Común del Sur. Ellas se desprenden del carácter "proteccionista" del aumento tarifario externo, en lo que concierne a bienes manufacturados de consumo final, cuyo efecto -en el caso que se revisase la naturaleza "comercialista" del Mercosur y se buscaran estrategias para "profundizar" los aspectos económicos y sectoriales- podría conducir a un nuevo esquema, más cerrado del modelo de integración. Sin embargo, a la par de este supuesto animus proteccionista, están las propuestas -en principio aceptadas por Brasil para rediscutir el AEC y, aún más, eventualmente reducir el Mercosur a una simple zona de libre comercio (BernalMeza, 2001a).

Las medidas de reducción de aranceles para bienes de capital, piezas y partes se complementaron con un aumento de los aranceles de importación de bienes de consumo final, llevándolos hasta un $35 \%$, que es el máximo que permite la Organización Mundial de Comercio. Iincluirá aquellos productos comercializados dentro del Mercosur que hasta ahora estaban liberados de aranceles. Las medidas proteccionistas regirán hasta diciembre de 2002

La reducción arancelaria generó el primero de los conflictos políticos con Brasil durante la gestión de De la Rúa. Como sabemos, el presidente Fernando H. Cardoso anuló su visita a Buenos Aires, programada para los días 16 y 17 de abril, como muestra de desagrado contra lo que se considera una medida que afectaba directamente las exportaciones brasileras a la Argentina, que rompía con los acuerdos arancelarios negociados en el Mercosur. ${ }^{27}$

Posteriormente hubo un mejoramiento relativo en las relaciones bilaterales, ya que el gobierno argentino aumentó al $14 \%$ los aranceles de productos de comunicaciones y computación extra Mercosur (5 de abril de 2001).

La "segunda etapa" de conflictos bilaterales se suscitó a partir de la decisión arancelaria argentina (Resolución 258/ 01 del Ministerio de Economía del 2 de julio pasado), de reducir las tarifas de importación de 500 productos de fuera del Mercosur, al permitir a los exportadores -del bloque y extra Mercosur-que descuenten al pago del impuesto de importación la diferencia de $8 \%$, según el nuevo cambio de comercio exterior ${ }^{28}$ justificada por la devaluación constante del real y para mejorar la competitividad nacional, y de los dichos poco diplomáticos del ministro Cavallo para referirse al país vecino. Estas situaciones generaron una nueva ola de conflictos, no sólo comerciales, entre los dos principales socios del bloque.

Las medidas crean un perjuicio potencial para los exportadores brasileños de bienes de informática, telecomunicaciones, bienes de capital y vehículos y constituyen un cambio unilateral respecto de los entendimientos alcanzados por los dos gobiernos, en Asunción, recientemente, pero se basan en el hecho que 
la moneda brasileña se devaluó más de un diez por ciento en los últimos sesenta días ${ }^{29}$ y supone una falta de decisión política de las autoridades monetarias de ese país para frenar el alza constante de la moneda norteamericana. Brasil ha reaccionado sugiriendo que podría retaliar las importaciones argentinas y amenazó con interrumpir las negociaciones que el bloque está llevando a cabo con la Unión Europea.

Respecto de la incorporación del euro a la canasta de monedas de la convertibilidad, además del aspecto puramente monetario, está el componente político externo. Si bien el anuncio tenía varias lecturas,${ }^{30}$ incorporar al euro es, en cierta forma, acercar a la Argentina a la Unión Europea, expresando de ese modo la voluntad del gobierno de mantener una posición cercana tanto a la órbita de la economía norteamericana (y de ALCA) como de la Comunitaria; asimismo, puede mejorar las relaciones entre Europa y la Argentina, tal como opinan algunos ejecutivos de finanzas europeos, en el sentido que la introducción de esa moneda y el acercamiento a Europa puede permitir al gobierno una gestión económica menos cíclica y vulnerable ante las coyunturas, a la par de que es un aliciente para mayores inversiones. ${ }^{31}$

No obstante estas argumentaciones, teniendo en perspectiva que la moneda europea, más tarde o más temprano terminará compitiendo con el dólar, es posible también imaginar que Cavallo haya considerado como una cuestión de realpolitik la incorporación a la zona del euro, buscando un lugar en la disputa de poder económico entre Europa y Estados Unidos.

\section{El Cambio de Visión Argentino sobre el Brasil}

Para el nuevo grupo que maneja la política económica argentina, Brasil es visto como un socio que sufre grandes inestabilidades cambiarias y económicas. Se sostiene entonces que la inserción argentina, sin descartar el Mercosur, debe dirigirse hacia otros bloques comerciales, en particular el NAFTA. La idea es que este acercamiento aseguraría la estabilidad macroeconómica argentina.

\section{Visión de Cavallo sobre el Mercosur y las Percepciones de Otros Actores}

En un libro que coincidió con su llegada al Ministerio de Economía, Cavallo sostiene que "el arancel externo común no le conviene a nadie". Más tarde, en público señaló que "el Mercosur debería concentrar sus esfuerzos en expandir el libre comercio hacia el resto de los países de Sudamérica y en lograr la plena integración de todos sus factores de producción, lo que era mucho más importante que discutir por el Arancel Externo Común". ${ }^{32}$

Vale la pena destacar que el Mercosur ha sido señalado por el gobierno argentino como un objetivo estratégico, parte de la "política de Estado argentina" e instrumento clave para la inserción y negociación externa. Como expresó el presidente De la Rúa, "el Mercosur es nuestra gran fuerza y debemos ir al ALCA desde esa base"; agregando que "Brasil sólo pidió que el ALCA no se concretara antes de 2005 y se respetó ese pedido". ${ }^{33}$

Raúl Alfonsín y Carlos Alvarez, los máximos referentes políticos de la Alianza UCR-FREPASO, plantean que, como objetivo de política hemisférica, el gobierno argentino debe fortalecer el Mercosur y, sobre todo, la relación con Brasil. En encuentros realizados desde fines de mayo, han venido propiciando un debate -junto a otros espacios de reflexión- sobre el presente y futuro de la Argentina frente al mundo, en el cual sitúan, como eje de la discusión- el posicionamiento del país frente a ambos escenarios de integración. Para ambos dirigentes políticos, se debe privilegiar, sin excepción, la restauración de la relación con el gobierno de Fernando H. Cardoso, antes que cualquier aspiración o sueño inspirado en los Estados Unidos; abogando asimismo por un mayor apoyo a la posición sostenida por el canciller, en su disputa con Cavallo. Según los aliancistas, "el Mercosur es un serio proyecto estratégico de integración económica y política que no debe deshacerse". ${ }^{34}$

Sin embargo, más que atender a las declaraciones, lo que se debe tener en cuenta es que para el actual gobierno, así como lo fue para el anterior, el tema sigue siendo la vinculación entre los dos escenarios: Mercosur y ALCA. La relación entre ambos proyectos pasa por el futuro que ambos países, Argentina y Brasil, decidan sobre el bloque subregional, frente al cual siguen presentes los tres escenarios posibles: unión aduanera, zona de libre comercio o continuidad del statu quo (unión aduanera incompleta o en lenta construción). Pero la sociedad argentina se manifiesta más escéptica sobre el futuro del bloque. Según una encuesta realizada a fines de abril de 2001, el Mercosur tiene $29 \%$ de imagen positiva en la opinión pública argentina, contra sólo 12\% de ALCA. La imagen del bloque subregional ha venido descendiendo según las percepciones y expectativas fueron reduciéndose, a la luz de las dificultades entre Argentina y Brasil. Ese desgaste se advierte en el descenso de la imagen positiva que tenía 
el Mercosur en 1993, que era de 45\% y que para 1997 se había reducido al $38 \% .{ }^{35}$

\section{Las Relaciones con la Unión Europea}

Las relaciones, principalmente económicas, se han manejado preferentemente bloque a bloque (MercosurUnión Europea), en la medida de las coincidencias sudamericanas de la agenda, con excepción de los temas agrícolas específicos, como la suspensión de las importaciones de carne argentina debido a los brotes de aftosa. Esa perspectiva se basa en el hecho que las relaciones bilaterales, excelentes en el plano político, pasan prioritariamente por los temas del comercio, frente a lo cual la Política Agrícola Común de la UE se transforma en el principal impedimento para alcanzar un equilibrio comercial, pues el comercio argentino con esa región es históricamente deficitario.

Las relaciones comerciales de la Argentina con la UE son significativas. En 1999, el 66\% de las inversiones en al país fue realizado por empresas europeas.

Después de la frustración de la Cumbre de Río, donde no hubo progresos en torno al tema agrícola, la Unión Europea ofreció, durante el mes de junio de 2001, incluir algunos de los temas candentes, en la siguiente ronda de negociaciones bilaterales Mercosur-UE, en Montevideo.

Según Roberto Lavagna, representante argentino ante la UE, los tres puntos que pretende debatir el bloque del Cono Sur son: el acceso a los mercados, que abarca la eliminación de tarifas, barreras no-arancelarias y medidas sanitarias y fitosanitarias que a menudo frenan el ingreso de agroalimentos en la UE; la supresión de los subsidios a las exportaciones europeas hacia el Mercosur; finalmente, la restricción de las subvenciones a los productos comunitarios que compiten con los del bloque sudamericano en terceros mercados, por caso, en el resto de América del Sur. ${ }^{36}$

De acuerdo a declaraciones del embajador argentino, la Unión Europea derivará a la OMC el debate sobre las reglas sanitarias y fitosanitarias, dejando para la cumbre de Qatar la discusión sobre las ayudas a las exportaciones en el nivel general y a los productos que se venden dentro del mercado común, desestimando que haya flexibilizado su postura respecto de la política agrícola. ${ }^{37}$

Respecto de las relaciones bilaterales país-a-país, éstas se inscriben casi exclusivamente en el ámbito econonómico, aunque con España las mismas fueron definidas por el presidente del Gobierno español como de una alianza estratégica. Esta identificación de las relaciones bilaterales, asociados a la situación económica y financiera argentina -que afecta a la economía española, en virtud de las cuantiosas inversiones de empresas españolas en Argentina- fue puesta de manifiesto durante la primera visita oficial del presidente Bush Jr. a España. En esa oportunidad, Aznar planteó el tema de Argentina durante la reunión con Bush en la finca estatal de Quintos de la Mora, en Toledo. Analizando la situación latinoamericana hizo referencia a la necesidad de apoyar los "esfuerzos de recuperación" que realiza actualmente el gobierno argentino.

Sin embargo, las relaciones - a nivel de sociedades y del mundo de los negocios-se han deteriorado sensiblemente, como consecuencia de la crisis de la empresa Aerolíneas Argentinas (que luego de su privatización pasó a manos españolas), llevada a situación de quiebra por sus propietarios, la SEPI española. La intransigencia del gobierno español, de considerar el hecho como una cuestión puramente "empresaria" motivó, por primera vez en la historia contemporánea, masivas manifestaciones antiespañolas en Argentina, al punto de llamar la atención del gobierno madrileño, quien apeló a los lazos históricos que unen a ambas sociedades, advirtiendo sobre los riesgos que esa situación generaba para los negocios e inversiones. Las autoridades españolas de Aerolíneas Argentinas, aduciendo problemas financieros que le impedían pagar la provisión de combustible fuera de Argentina, suspendió los vuelos, primero, aquellos con destino a Europa, Estados Unidos, Brasil y Australia y luego los de cabotaje. Frente a esta situación, el gobierno argentino, intimó a la empresa a mantener los vuelos y amenazó con quitarle la concesión de las rutas. La situación parecía mantenerse en un impasse, al menos hasta mediados de agosto, fecha para la cual el directorio de la empresa pospuso una decisión sobre su destino, mientras, por otra parte, continuaba buscando eventuales compradores para su traspaso.

Las inversiones españolas en Argentina, de 32 mil millones de dólares al comenzar el año 2000, representaban más del $25 \%$ del total de inversiones entranjeras, lo que transforma a ese país en el segundo inversor externo. No obstante, según estimaciones actuales, las inversiones españolas alcanzarían una cifra cercana a los 40 mil millones, ubicándose así en el primer lugar del ránking de inversiones extranjeras.

Las relaciones con Francia e Italia mantienen su tradicional buen vínculo político, aunque en ambos casos no hubo apoyo financiero específico para la Argentina en su reciente crisis. Los temas principales de la agenda de la 
vista del canciller francés Hubert Vedrine a Buenos Aires, se concentraron en torno a los problemas judiciales que enfrentan algunas empresas francesas, como Renault, Aguas del Aconquija y Partouche. En el caso de la primera, la Aduana argentina le aplicó una multa de 519 millones de dólares por supuesto contrabando. En tanto, en los temas políticos, Francia no ha manifestado una voluntad de apoyar la causa argentina de Malvinas, en contra de Gran Bretaña.

\section{LA OSCILACIÓN ENTRE WASHINGTONY BRASÍLIA: LA CONTINUIDAD DE LA INCERTEZA}

Más allá de una predisposición hacia una continuidad de relaciones más estrechas con Washington, el gobierno de Dela Rúa ha sido fuertemente condicionado por la gravedad de la situación económica y financiera heredada y que fuera agravada por las débiles y erráticas políticas implementadas en los primeros 15 meses de gobierno. En ese contexto, el gobierno argentino dependió del apoyo norteamericano para la obtención del "blindaje" ${ }^{38}$ por u $\$ \mathrm{~s}$ 40.000 millones y luego para enfrentar nuevos acuerdos con el FMI y la renegociación de sus deudas de corto plazo con la banca internacional privada. La posición crítica de Argentina, respecto de Cuba, incluyendo su voto junto a EE.UU. (aún cuando la Argentina manifestara su oposición al embargo norteamericano), así como una predisposición inicial a adelantar las negociaciones por ALCA -luego desechadas por el gobierno de De la Rúa- deben ser leídas en ese contexto.

Además de esa situación coyuntural, la llegada al gobierno del ministro Cavallo evidentemente fortaleció las posiciones pro-ALCA y a favor de un acuerdo bilateral con Estados Unidos, en la medida que éste y los sectores políticos de su entorno siempre manifestaron su opción preferente por una integración con Washington. Sin embargo, la posición oficial del gobierno argentino, expresada por su canciller y por el propio De la Rúa, siempre fue respetar el compromiso del país con el Mercosur, incluyendo negociar "como bloque" por ALCA.

Ambas alternativas, Mercosur y ALCA, aparecen como distintas y, a la vez, complementarias; pero esto es así también para Brasil. Las relaciones políticas bilaterales, que tuvieron como núcleo de divergencias las respectivas relaciones con Estados Unidos y las políticas de seguridad, durante la gestión del presidente Menem (Bernal-Meza, 1999), se recompusieron, bajo promisorias perspectivas, luego de la asunción de De la Rúa, hecho que se reflejó en las coincidencias de Florianópolis y posteriormente en los acuerdos sobre coordinación macroeconómica; pero se deterioraron a partir de las primeras medidas heterodoxas de Cavallo.

No obstante, el gobierno argentino hizo un gesto de significativa relevancia política, al adelantar al gobierno de Cardoso las medidas que pensaba implementar respecto de la política cambiaria. A partir de allí, el gobierno brasileño otorgó pleno apoyo a las mismas y se cerraron coincidencias en torno al futuro del Mercosur, respecto de su AEC y de la decisión de nombrar un solo negociador "coordinador", junto a los cuatro respectivos representantes, para las discusiones con Estados Unidos sobre ALCA.

A pesar de estas coincidencias, el desafío conjunto sigue siendo la preservación del Mercosur como un subsistema regional, cuyo liderazgo responda exclusivamente a las prioridades y objetivos del desarrollo económico y de la inserción de ambos países en el sistema mundial.

Argentina logró su objetivo de transformar el proyecto "Mercosur" en un escenario de expansión comercial. Tuvo un creciemiento del comercio y un aumento de las exportaciones al Brasil. Su balanza comercial bilateral fue superavitaria durante gran parte del período. Pero la desviación de comercio generada por el Mercosur, a pesar del componente de mayor valor agregado (manufacturas de origen industrial), que alcanzaron cerca del $40 \%$ de las exportaciones totales al Brasil, en términos globales acentuó el carácter primario de sus exportaciones, generando un subsistema centro-periferia de intercambios bilaterales, con el cual la Argentina profundizaría su inserción internacional basada en ventajas comparativas estáticas. Por su parte, dentro del patrón de comercio norte-sur que ha caracterizado históricamente el comercio bilateral argentino-norteamericano, éste fue deficitario para

\begin{tabular}{lccc}
\multicolumn{4}{c}{$\begin{array}{c}\text { CUADRO 1 } \\
\text { Balanza Comercial Argentina-Brasil } \\
\text { 1995-2001 }\end{array}$} \\
\hline Año & \multicolumn{3}{c}{ En millones u\$s } \\
\hline & Importaciones & Exportaciones & Saldo \\
1995 & 4.041 & 5.591 & 1.550 \\
1996 & 5.170 & 6.805 & 1.635 \\
1997 & 6.770 & 8.032 & 1.262 \\
1998 & 6.748 & 8.034 & 1.286 \\
1999 & 5.364 & 5.812 & 448 \\
2000 & 6.233 & 6.843 & 610 \\
Enero-Abril/2001 & 1.870 & 2.179 & 309 \\
& & & \\
\hline
\end{tabular}

Fuente: INDEC, Ministerio de Economía, Rep. Argentina 
Argentina. Comparativamente, mientras que el comercio con Brasil, entre 1995 y 2000 arrojó un saldo positivo de u\$s 5.335 millones, el comercio con EE.UU. resultó negativo, en igual período, por u\$s 17.029 millones.

Según cifras de INDEC, para el año 2000 las exportaciones argentinas de manufacturas de origen industrial hacia el Brasil totalizaron u\$s 3.300 millones $(40,2 \%$ del total), mientras que hacia los Estados Unidos este sector sólo representó u\$s 1.080 millones (13,1\% del total).

En este contexto, ¿cómo explicar las posiciones contrarias a una integración cuyo comercio bilateral ha sido positivo?

Uno de los argumentos, de orden económico-estructural, se ha fundado sobre el carácter centro-periferia del comercio. Pero otro, político, se ha sostenido, permanentemente, sobre una visión negativa respecto del Brasil, en relación a los pocos avances de coordinación alcanzados entre ambos países y a las posiciones divergentes en política exterior, en particular las que se expresan en las respectivas relaciones con Estados Unidos y sus agendas.

En relación a las opciones, entre Alca y Mercosur, en el espectro político argentino existen dos claras posiciones: aquella representada por los sectores "cavallistas" (incluyendo al menemismo) y la que representan los máximos referentes de la coalición de gobierno, Raúl Alfonsín y Carlos Alvarez. Estos últimos plantean como meta fortalecer el Mercosur y, sobre todo, la relación con Brasil.

En la sociedad argentina se advierten posiciones encontradas respecto de lo que deberían ser las alianzas externas de Argentina. Una encuesta, sobre la relación del país con los Estados Unidos, reveló que ésta es considerada una cuestión muy importante por el $69 \%$ de los consultados, aunque quienes opinan en favor de esa cuestión son los encuestados con mayor poder adquisitivo. Para el $69 \%$ de los consultados por Gallup, la relación con el país del Norte es muy importante, mientras que un $24 \%$ opina que es poco o nada relevante y sólo un $7 \%$ no tiene opinión formada sobre el tema. ${ }^{39}$

La percepción de la diplomacia y la prensa brasileñas es que el gobierno argentino habla por boca de Cavallo, persona que nunca tuvo buena imagen en Brasil, dada su reconocida filiación pro norteamericana (ALCA) y su visión crítica sobre el Mercosur. Sin embargo, ésta es una percepción equivocada: es el presidente De la Rúa quien decide la política. Pero, ¿por qué éste ha permitido que Cavallo maneje su política bilateral con el gobierno brasileño? La respuesta tiene que ver con las limitaciones propias que la situación económico-financiera argentina impone y la dependencia que el gobierno tiene de la figura de Cavallo como su ultima ratio, dentro de la continuidad del modelo de ajuste estructural.

Pero muchos empresarios, diplomáticos, economistas y académicos continúan considerando que la mejor opción argentina sigue siendo el Mercosur; que éste es una "política de Estado" y que las relaciones con Brasil son muy importantes para la Argentina y que seguirán siéndolo por mucho tiempo. ${ }^{40}$

La nueva situación de conflicto, creada a partir de las medidas del gobierno argentino para enfrentar la crisis del 2001, pone de relevancia tres aspectos: en primer lugar, no es posible identificar cuánto del poder que pidió Cavallo de injerencia de Economía en la política exterior, como parte de las negociaciones para su ingreso al equipo gobernante de De la Rúa, le fue concedido por éste. No obstante, de la permanente incursión de Cavallo en las relaciones bilaterales argentino-brasileñas, se deduce que el perfil de la gestión externa de Giavarini ha sido, en los hechos, manifiestamente reducido. Las medidas arancelarias del ministerio de Economía argentino marcan también la libertad que tiene Cavallo para incursionar en las relaciones internacionales del país.

En segundo lugar, las últimas medidas arancelarias de Cavallo-que objetivamente no mejorarán la situación de la economía argentina en el corto plazo (ya que la recuperación del crecimiento y del empleo requieren de tiempo y políticas de reasignación recursos, así como del mejoramiento del poder adquisitivo de los trabajadores)- ponen en cuestionamiento las relaciones económicas bilaterales. Resulta incomprensible que De la Rúa haya aceptado una estrategia de deterioro político con Brasil cuando este país provee a la Argentina de un mercado de intercambio superavitario y que es el eje del único bloque comercial del mundo con el cual se tiene un superávit comercial permanente.

Por último, las medidas arancelarias argentinas ponen de relevancia las fragilidades del Mercosur. En primer lugar, porque su evolución sigue condicionada por los resultados de los programas económicos nacionales de ajuste, estabilización y reformas. En segundo lugar, el camino sin salida frente a las medidas unilaterales, por ausencia de una estructura institucional (supranacional) que proteja a todas las economías de las decisiones autónomas e individualistas. En este sentido, Brasil está tomando de su propia medicina, pues sistemáticamente se opuso a la creación de órganos comunitarios supranacionales y ahora, frente a la situación de una medida unilateral, sólo le que- 
da el camino de la suspensión de negociaciones comerciales. Así, el modelo de institucionalidad elegido por los cuatro países y que Brasil ha insistido en mantener, deja a los países miembros ante un camino sin salida frente a los conflictos -que naturalemente deberán continuar, tal como otras experiencias históricas lo demuestran $-{ }^{41}$ por la ausencia de una instancia negociadora y reguladora de carácter superior.

Esta evaluación debe ser contextualizada en una percepción de deterioro de las relaciones bilaterales. Más allá de las declaraciones "formales" de solidaridad, gobierno a gobierno, en relación a las respectivas conflictivas situaciones internas, la política seguida por Argentina y Brasil hacia su vecino, durante el presente año, es lo más semejante al puro realismo, con actitudes mutuas de "sálvese cada uno, por sus medios y como pueda".

Argentina y Brasil, por tanto también el Merosur, no lograron -a pesar del recambio presidencial argentinoestablecer una agenda bilateral, regional y multilateral común; en este último caso, con la excepción de las negociaciones por Alca y con la Unión Europea.

\section{CONCLUSIONES}

Tal como señalamos en un documento que hacía prospectiva, no podían esperarse grandes cambios en la política exterior. Las diferencias estarían más en las actitudes y las formas que en los contenidos (BernalMeza,1999a). La Argentina no abandonaría su aspiración a transformarse en el principal interlocutor de Estados Unidos en América del Sur, ahora a través de una política de "bajo perfil", cuyo principal eje pasa por la adhesión a los proyectos económicos norteamericanos (ALCA).

El gran cambio en política exterior debería haber venido como consecuencia de un cambio en el modelo económico vigente desde 1976 (con un breve interludio bajo Alfonsín); pero De la Rúa prefirió la continuidad.

Las pequeñas diferencias en política exterior, de Menem a De la Rúa, están en un retorno del interés por Europa, en particular España -hoy el principal inversor externo en la Argentina- y en las apelaciones por el fortalecimiento de los consensos multilaterales, aspirando a una mayor democratización de Naciones Unidas. En definitiva, más allá de las diferencias de estilo, la política exterior de De la Rúa no ha hecho mucho por diferenciarse de la anterior.

La Argentina vive hoy una de las etapas terminales de la crisis del modelo de inserción neoliberal (Bernal-Meza, 2001; 2001b). El fracaso de los sucesivos modelos de desarrollo e inserción internacional influyó en la política exterior, marcando ésta con una línea de continuidades, cambios y rupturas significativas, reflejándose en etapas de alineamiento - con Gran Bretaña primero-, de autonomización y de nuevos alineamientos (con Estados Unidos, durante parte de las décadas de los 50, 60 y 70), para llegar al período de nuevo alineamiento e inserción subordinada de los noventa. Sin embargo, bajo esas "incoherencias superficiales", existió una coherencia estructural que permitió explicarla (Puig, 1984;1988), primero, a través de la imagen del país que percibían sus élites, luego, por las relaciones entre modelo económico e inserción externa.

El abandono definitivo de las estrategias de sustitución de importaciones y la adopción de una inserción en los mercados internacionales de capital, por sobre la opción de una inserción productiva de carácter industrial, requería de una política exterior de alineamiento con las potencias del capitalismo central y, principalmente con Estados Unidos. Sin embargo, el resultado -en términos económicos y de desarrollo- fue un fracaso, que se manifiesta en el carácter estructural de la actual crisis (Bernal-Meza, 2001)

De la Rúa ha tenido un fuerte condicionamiento político derivado de la situación económica y financiera heredada, agravada por las débiles políticas implementadas en estos primeros 15 meses de gobierno, y dependió del apoyo norteamericano para la obtención del "blindaje" financiero y luego para enfrentar nuevos acuerdos con el FMI y la renegociación de sus deudas de corto plazo con la banca internacional privada. La posición crítica respecto de Cuba, incluyendo su voto junto a EE.UU. (a pesar de la oposición al embargo) y la predisposición a adelantar las negociaciones por ALCA deben ser leídas en ese contexto.

El Mercosur y las relaciones Estados Unidos/ALCA siguen siendo el tema más relevante y de complejo pronóstico de la política exterior. La posición oficial del gobierno argentino continúa siendo la de mantener la vigencia del Mercosur y que negociará ALCA en acuerdo con los restantes socios del bloque subregional. Pero esta decisión ha sido también relativizada, según lo cual, la voluntad norteamericana por profundizar su compromiso de constituir el mercado hemisférico, acelerando los plazos y el estado de las relaciones con Brasil podrían influir en un cambio de posición.

Algunos temas de la agenda y objetivos de la política exterior, que fueron altamente relevantes bajo la gestión del presidente Menem, como los relacionados con la seguridad y la defensa, han sido reducidos drásticamente en su perfil. A pesar de que ello implica una preferencia 
por una agenda de "baja política", la política exterior argentina actual no se ha caracterizado por una gestión internacional activa en lo que constituyen los asuntos más relevantes de los nuevos temas internacionales, como el impacto de las nuevas tecnologías, la degradación del medio ambiente, los delitos electrónicos y las patentes medicinales.

La sítensis de la agenda argentina, a partir de diciembre de 1999, señala que ésta continuó con dos de los tres temas relevantes de la gestión Menem: 1) proyección externa de la "reformulación de la estrategia nacional de desarrollo y reinserción en el Primer Mundo" (en la medida que hay continuidad del modelo económico neoliberal y una preferencia por el relacionamiento con las grandes potencias capitalistas occidentales, en particular con Estados Unidos) y 2) adopción de la "agenda de valores hegemónicos universalmente aceptados"; mientras que el tercero, crear para Argentina una zona de paz en el cono sur, que se traducía en la adhesión a la nueva concepción de seguridad de los Estados Unidos, no ha sido motivo de preferencia alguna.

Por su parte, los Objetivos de la política exterior, todos ellos se mantienen respecto del pasado, excluyendo los temas de seguridad, en relación a la agenda argentinonorteamericana y el ingreso a la OTAN, vista por el radicalismo como inviable y no conveniente para el mejoramiento de las relaciones con Brasil. A pesar de ello, las relaciones con el país vecino no lograron traspasar la barrera de los problemas comerciales.

Por último, en relación al carácter de la política exterior, se advierten algunos cambios y continuidades. En primer lugar, si bien la "comunidad epistémica" que sustentara el modelo del realismo periférico está fuera del gobierno, su influencia sigue proyectándose en la política externa, en la medida que no ha habido un cambio del eje de las preferencias externas, hacia el Mercosur y las relaciones con Brasil, aún cuando no puede hablarse hoy de un "alineamiento" de la Argentina con Estados Unidos, que -supuestamente- fuera el núcleo de las divergencias durante el gobierno anterior. Esta continuidad de la influencia está dada tanto por los contenidos (agenda y objetivos) como por la incidencia que el ministro Cavallo - quien formó parte del staff que implementó la política exterior menemista- tiene en la conducción de las relaciones internacionales del país. En segundo lugar, la política exterior actual se caracteriza por su bajo perfil y una ausencia de "diplomacia presidencial". La figura del Presidente ha sido más bien pasiva, mientras que la del ministro Cavallo ha sido altamente relevante, tal como se desprende de los análisis que aquí efectuamos.

\section{NOTAS}

1. En forma llamativamente similar a la que se formuló en Brasil con el "pragmatismo ecuménico responsable"; Cfr. Bernal-Meza (2000).

2. El sentido que damos aquí al desarrollismo deriva de las interpretaciones sobre el proceso de transformaciones del sistema mundial y de las políticas nacionales necesarias para enfrentar sus desafíos. Esta visión mantenía continuidades como el neokeynesianismo, respecto del papel del Estado como conductor del desarrollo y actor esencial de la asignación de recursos y del realis$m o$, en la percepción de las características de un sistema internacional dominado por los imperativos del poder.

3. Desarrollado por Peter Haas, bajo la denominación de "comunidades epistémicas" el concepto ha sido tomado por Amado Luiz Cervo (2000:5-27), para aplicarlo al conjunto de intelectuales, académicos y diplomáticos argentinos que con sus aportes ayudaron a formular la base de sustentación ideológica de la política exterior de Menem, que fuera implementada por lo cancilleres Cavallo y Di Tella (Bernal-Meza, 2000:353).

Todos ellos, según Cervo (1999; 2000), tenían en común una visión revisionista de la historia argentina. Estaba integrada, entre otros, por Tulio Halperin Donghi, Carlos Escudé, Felipe de la Balze, Jorge Castro y Andrés Cisneros.

4. Hemos definido éstos como aquellos que constituyen la esencia de la agenda post-guerra fría, bajo el orden imperial, que sustituyeron los temas relevantes de la agenda internacional de los años 70 y 80 . Estos valores, que sustentan ahora la nueva configuración del sistema internacional, como el liberalismo económico, los derechos humanos, la protección ambiental, los derechos sociales, junto a los temas militar-estratégicos -bajo nuevas formas, vinculadas a los nuevos conceptos de la seguridadexcluyen el tema del "desarrollo". Cfr. Bernal-Meza (2000:91-92). Asimismo, constituyen el fundamento de los instrumentos para mejorar -supuestamente- la inserción internacional de los países en desarrollo, bajo el nuevo orden político y económico de la globalización (Bernal-Meza, 2000:155).

Algunos autores los han definido como valores hegemónicos internacionalmente reconocidos (Vigevani, et alii, 1999).

5. Si bien bajo la gestión de Alfonsín se había comenzado a reformular el rol del Estado, sobre todo desde el ministerio conducido por Terragno, con Menem el proceso de reforma y privatizaciones del Estado se acelera, bajo el paradigma neoliberal.

6. Para la interpretación "fundamentalista" o "ideológica" de la globalización, ver Ferrer (1998) y Bernal-Meza (1996; 2000), respectivamente.

7. Ver, a este respecto, Bernal-Meza (1994), segunda parte, capítulo primero.

8. Escudé señala la irrelevancia de las modificaciones del sistema internacional para la elaboración de una adecuada política exterior del país.

9. Sin embargo, como se ha advertido, respecto de este tema se daría una gran paradoja: mientras el discurso y las argumentaciones sugerían una "política de bajo perfil" (o de "baja política"), lo que se hizo fue todo lo contrario. Cfr. Bernal-Meza (2000).

10. Aunque éste fue un objetivo importante de Alfonsín, a quien se deben los grandes beneficios de la nueva relación de Argentina con la Unión Europea y sus países miembros, especialmente España e 
Italia, países con los cuales durante su gestión se firmaron importantes convenios económicos, financieros y comerciales.

11. Como señala Bologna (1998:13), citando prensa de la época, esta línea de acción diplomática había sido sugerida al presidente Menem, antes de asumir el cargo, por el presidente del gobierno español, Felipe González, quien le manifestó que si quería poner un pie en el Mercado Europeo, antes tenía que arreglar el tema Malvinas con los ingleses.

12. Decimos "aplicación" porque los términos de éste habían sido acordados entre ambos países durante la gestión de Alfonsín.

13. Como señalan Busso y Bologna (1994:51), "el gobierno de Menem no concentró un alto nivel de expectativas en este ámbito. "Si bien Buenos Aires fue sede de la reunión cumbre realizada en noviembre de 1992, la actividad del Grupo no fue trascendente. Esta apreciación se sustenta en nuestra percepción sobre la existencia de un cambio en este proceso de concertación política que va de un enfoque resolutivo a uno más deliberativo. En sus orígenes lo caracterizábamos como un espacio de resolución de temas pero, actualmente se ha convertido en una sociedad de debate. Por otra parte, la influencia del alineamiento argentino con Estados Unidos se hizo presente en la Cumbre de Buenos Aires. El Presidente Menem efectuó contactos telefónicos con el entonces presidente George Bush y con el presidente electo Bill Clinton, comunicándoles los objetivos de la reunión. Esta actitud argentina no contó con el aval de los otros miembros. Por otra parte, la disparidad de posiciones entre Argentina y otros integrantes ante la cuestión cubana también puede ser interpretada como una consecuencia de la dinámica del alineamiento".

14. "Discurso del canciller Adalberto Rodríguez Giavarini sobre la política exterior argentina”, Dirección de Prensa, Ministerio de Relaciones Exteriores, Comercio Internacional y Culto, Buenos Aires, 30 de mayo de 2000.

15. "Rodríguez Giavarini bregó por la reducción del proteccionismo económico para reducir la marginación social"; Dirección de Prensa, Ministerio de Relaciones Exteriores, Comercio Internacional y Culto, Buenos Aires, 27 de septiembre de 2000.

16. Esta fue una desgraciada expresión, con la cual el entonces canciller argentino, Guido Di Tella, quiso ejemplificar el nuevo modelo de relaciones que la Argentina aspiraba a mantener con Estados Unidos.

17. Las relaciones con Cuba se deterioraron a partir de la filtración de la noticia que detallaba la posición que adoptaría la Argentina en la Comisión de Derechos Humanos de la ONU." En el acto por el 1 de mayo en la Habana, Fidel Castro acusó al gobierno argentino de ser "monigote de los yanquis". Como respuesta, el gobierno argentino, con fecha 5 de mayo, hizo permanente el retiro de su embajador en Cuba, que ya estaba en Buenos Aires desde febrero pasado, quedando las relaciones diplomáticas al borde de la ruptura.

18. Según declaró la Secretaria de Política Exterior, Susana Ruiz Cerutti, "nuestro único interlocutor es Gran Bretaña. Los isleños no son ni serán parte de la controversia", La Nación, "El Gobierno no dialoga con los isleños", Buenos Aires, 22/02/2001.

19. Clarín, "Apuran los tiempos de la cita entre Clinton y De la Rúa”, Buenos Aires, 08/02/2000.

20. El gobierno de Carlos Menem otorgó la adjudicación a la empresa norteamericana Northop, asociada a la italiana Alenia, pero la misma fue suspendida por una medida judicial.

21. La Nación, "EE.UU continúa molesto con la SIDE. Colin Powell planteó a Rodríguez Giavarini la falta de cooperación del organismo de inteligencia"; Buenos Aires, 13/05/2001.

22. Según señaló la prensa, la síntesis de la estrategia inicial de Cavallo frente al Mercosur y ALCA era un "replanteo total del Mercosur". Según Gazeta Mercantil (semana del 26 de marzo al 1 de abril de 2001), citando declaraciones de uno de los asesores del ministro al diario El Cronista, la reformulación del Mercosur pasaba por: "Primero implica exigir de Brasil una rápida constitución de un verdadero mercado común. Como Brasil no lo va a hacer, eso nos dría libertad de acción y pasaríamos a una zona de libre comercio, donde recuperaríamos toda nuesta libertad comercial, y eso nos permitiría buscar un acuerdo bilateral con Estados Unidos".

23. Clarin.com, Economía, miércoles 09/05/2001.

24. "Há preocupação no Brasil", Gazeta Mercantil Latino-americana, Rio de Janeiro, edición del 14 al 20 de mayo de 2001, p.23.

25. Clarín, Buenos Aires, 13/04/2001.

26. En la reciente reunión del Mercosur en Asunción, el 21 de junio pasado, los cuatro países del bloque decidieron reducir en un punto porcentual la tasa de estadística general para las importaciones extra-Mercosur (del 2,5\% al 1,5\%), lo que en la práctica reduce el promedio actual del AEC de 13,5 a 12,5 por ciento.

27. "E1 presidente Fernando H. Cardoso suspendió la visita programada a Argentina para los días 16 y 17 de abril, como muestra de desagrado contra lo que se considera una medida que afecta directamente las exportaciones brasileras a la Argentina, que rompe con los acuerdos arancelarios negociados en el Mercosur", Folha de S.Paulo, 05/04/2001.

28. Entre las medidas del segundo "paquete", implementado por Cavallo durante su actual gestión, estaba una devaluación encubierta, del $8 \%$, que se aplica sobre los valores de importación y exportación, con lo cual el peso argentino tiene, para el comercio exterior, una equivalencia de $\mathrm{u} \$ \mathrm{~s} 1=\$ 1,08$.

29. Ya con anterioridad, el 25 de junio, Cavallo había amenzado a Brasil, Uruguay y Paraguay con más medidas si esos países continuaban devaluando sus monedas. El ministro argentino está convencido de que todas las devaluaciones regionales son producidas por los gobiernos y los bancos centrales y no por libres movimientos del mercado. Cfr. Ambitoweb, 26/06/2001.

30. La primera podía obedecer a un test para evaluar cómo los operadores económicos y la ciudadanía podrían reaccionar frente a la alternativa de una flexibilización del sistema de convertibilidad, que llevara posteriormente a una salida no traumática del mismo. La segunda, habría sido tranquilizar a los inversores españoles y en general a los europeos, acerca del hecho que la Argentina no se estaría volcando hacia una vinculación más estrecha con Estados Unidos y ALCA, postergando sus relaciones con la Unión Europea. 31. La Nación, 22/04/2001.

32. Domingo Cavallo, en la presentación de su libro Pasión por crear, 31/3/2001, p.12.

33. La Nación, Buenos Aires, 18/04/2001. En igual forma se expresó el vocero presidencial, Ricardo Ostuni, en conferencia de prensa del mismo día, previa al viaje de De la Rúa a Québec, cuando señaló que "la posición argentina es negociar desde el bloque regional del Mercosur. La Argentina negocia desde el Mercosur en el ALCA; esta es la resolución que se tomó aquí en Buenos Aires; es la posición del gobierno argentino".

34. La Nación, Buenos Aires, 19/06/2001.

35. Ambitoweb, "Encuesta: Mercosur mejor que ALCA", 22/05/ 2001 .

36. La Nación, "El Mercosur y la UE comienzan a negociar sobre aranceles", Buenos Aires, 01/06/2001.

37. Declaraciones del embajador Roberto Lavagna a La Nación, $01 / 06 / 2001$.

38. Apoyo financiero del FMI y de algunos países (España), por u\$s 40.000 millones, como recursos a disposición del gobierno argentino, a entregar en cuotas, de acuerdo a aceptación previa -por parte del organismo financiero internacional- de las medidas 
implementadas por la gestión económica, negociado durante la gestión del ministro José L. Macchinea.

39. La Nación Line, "Para los argentinos, la relación com los EE.UU. s muy importante", Buenos Aires, 12/06/2001.

40. Cfr. La Nación, "Voces a favor de mantener el Mercosur", Buenos Aires, 08/05/2001; también, Bernal-Meza (2001a).

41. De allí que la entonces Comunidad Económica Europea instituyó, como uno de sus primeros y esenciales instrumentos, la Corte Europea de Justicia, que fuera pieza clave en la dinamización del proceso de integración y para el efectivo cumplimiento de los acuerdos entre Estados.

\section{BIBLIOGRAFÍA}

BAUMANN, R. "Mercosul: Origens, Ganhos, Desencontros e Perspectivas". In: BAUMANN, R. (org.). MERCOSUL. Avanços e Desafios da Integração. Brasília, IPEA/CEPAL, 2001, pp. 1968.

BERNAL-MEZA, R. América Latina en la Economía Política Mundial, Buenos Aires, Grupo Editor Latinoamericano, 1994.

"La Globalización: ¿Un proceso y una ideología?". Realidad Económica, Buenos Aires, Instituto Argentino para el Desarrollo Económico, IADE, n. 139, pp. 83-99, abril-mayo 1996.

"Las percepciones de la actual política exterior argentina sobre la política exterior del Brasil y sobre las relaciones Estados Unidos-Brasil". Estudios Internacionales, Santiago, Instituto de Estudios Internacionales de la Universidad de Chile, año XXXII, n.125; pp. 51-82, enero-abril 1999a.

"Políticas Exteriores y Mercosur: reacciones ante una crisis". Carta Internacional, São Paulo, USP-Política Internacional, año VII, n.79, set. 1999 b.

Sistema Mundial y Mercosur. Globalización, Regionalismo y Politicas Exteriores Comparadas, Buenos Aires, Universidad Nacional del Centro de la Provincia de Buenos Aires/Nuevohacer/Grupo Editor Latinoamericano, 2000.

"Argentina. La crisis del desarrollo y de su inserción internacional”. Série Análisis e Informaciones. São Paulo, Fundação Konrad Adenauer e Programa de Estudos Europeos, Universidade Federal do Rio de Janeiro, n.1, maio 2001a.

"El Mercosur y las contradictorias políticas de Argentina y Brasil". Carta Internacional, São Paulo, USP-Política internacional, n.102, ago. 2001b.

"Argentina: ¿crisis coyuntural o estructural?”. Carta Internacional, São Paulo, USP-Política internacional, n. 99, pp. 7-10, maio 2001c.

BERNAL-MEZA, R. y LÓPEZ, R. "La nueva política exterior argentina". Carta Internacional, São Paulo, USP-Política Internacional, año VII, n. 82, p.6, dez. 1999.

BOLÍVAR, J. "La cuestión de la identidad en la nueva política exterior argentina". In: CISNEROS, A. (ed.). Política Exterior Argentina 1989-1999. Historia de un éxito. Buenos Aires, Grupo Editor Latinoamericano, 1998, pp.213-236.

BOLOGNA, A.B. "La inserción argentina en la sociedad internacional". In: CERIR. La Política Exterior Argentina 1994/1997. Rosario, Ediciones CERIR (Centro de Estudios en Relaciones Internacionales de Rosario), 1998, pp. 9-21.

BUSSO, A. y BOLOGNA, A.B. "La política exterior argentina a partir del Gobierno de Menem: una presentación". In: CERIR. La política exterior del gobierno de Menem. Seguimiento y reflexiones al promediar su mandato. Rosario, Ediciones CERIR, 1994, pp.17-51.

CARDOSO, O.R. "Un recuerdo que molesta". Clarín, Buenos Aires, $22 / 04 / 2000$

CASTRO, J. "La Argentina, Estados Unidos y Brasil: el triángulo de la década del 90". In: CISNEROS, A. (ed.). Política Exterior Argentina 1989-1999. Historia de un éxito. Op. cit. 1998, pp. 83-106.

CAVALLO, D.F. "La inserción de la Argentina en el primer mundo. 1989-1991". In: JALABE, S.R. (comp.). La política exterior argentina y sus protagonistas. 1880-1995. Buenos Aires, CARI (Consejo Argentino para las Relaciones Internacionales) Grupo Editor Latinoamericano, 1996, pp.357-378.

CERVO, A.L. "A política exterior da Argentina 1945-2000". Anuário de Política Internacional. Brasília, IPRI, 1999, mimeo.

"Sob o signo neoliberal: as relações internacionais da América Latina". Revista Brasileira de Política Internacional, Brasília, Instituto Brasileiro de Relações Internacionais, año 43, n. 2, pp.5-27, 2000.

CHIGHIZOLA, H. "Opinión de Negociador. Argentina y el ALCA". Archivos del Presente. Buenos Aires, año 6, n.21, julio-sep. 2000 .

CISNEROS, A. "Argentina: Historia de un éxito". In: CISNEROS, A. (ed.). Politica Exterior Argentina 1989-1999. Historia de un éxito. Op. cit. 1998, pp.35-82.

DI TELlA, G. "Prólogo". In: CISNEROS, A. (ed.). Política Exterior Argentina 1989-1999. Historia de un éxito. Op. cit. 1998, pp.13-17.

DE la BALZE, F.A.M. "La política exterior en tres tiempos. Los fundamentos de la nueva política exterior". In: DE la BALZE, F.A.M.y ROCA, E. (comp.). Argentina y EE.UU. Fundamentos de una nueva alianza. Buenos Aires, CARI/ABRA, 1997, pp.11-129.

"La política exterior de reincorporación al Primer Mundo". In: CISNEROS, A. (ed.). Política Exterior Argentina 1989-1999. Historia de un éxito. Op. cit. 1998, pp.107178.

ESCUDÉ, C. "De la irrelevancia de Reagan y Alfonsín: hacia el desarrollo de un realismo periférico". In: BOUZAS, R. y RUSSELL, R. (comp.). Estados Unidos y la transición argentina. Buenos Aires, Editorial Legasa, 1989, pp.243-272.

Realismo Periférico. Fundamentos para la nueva politica exterior argentina, Buenos Aires, Planeta, 1992.

El Realismo de los Estados débiles. La política exterior del primer Gobierno Menem frente a la teoria de las relaciones internacionales. Buenos Aires, Grupo Editor Latinoamericano, 1995.

FERRER, A. Hechos y ficciones de la globalización. Argentina y el Mercosur en el sistema mundial. Buenos Aires, Fondo de Cultura Económica, 1998.

PUIG, J.C. "La Política Exterior Argentina: incongruencia epidérmica y coherencia estructural". In: PUIG, J.C. (comp.). América Latina: Políticas Exteriores Comparadas. Buenos Aires, Grupo Editor Latinoamericano, v. 1, 1984, pp. 91-169.

"Política internacional argentina". In: PERINA, R. y RUSSELL, R. (ed.). Argentina en el mundo, 1973-1987. Buenos Aires, Grupo Editor Latinoamericano, 1988, pp.1945.

RUSSELL, R. Cambio de régimen y política exterior: el caso de Argentina (1976-1989). Buenos Aires, FLACSO, Serie de Documentos e Informes de Investigación, diciembre 1989. 
."Los ejes estructurantes de la política exterior argentina". América latina/Internacional. Buenos Aires, FLACSO, v.1, n. 2, pp. 5-26, otoño-invierno 1993.

VIGEVANI, T. et alii "Globalização e segurança internacional: a posição do Brasil". In: DUPAS, G. y VIGEVANI, T. O Brasil $e$ as novas dimensões da segurança internacional. São Paulo, Editora Alfa-Omega/FAPESP, 1999, pp. 53-86.
Raúl Bernal-Meza: Profesor de Relaciones Internacionales de la Universidad Nacional del Centro de la Provincia de Buenos Aires y Profesor de la Universidad de Buenos Aires. Director del Centro de Estudios de las Relaciones Internacionales de América Latina. Actualmente, Profesor Visitante de la Universidade de São Paulo (bernalmeza@hotmail.com). 